\title{
Skenario Perbaikan Nilai Keandalan Loss of Load Probability pada PLTH Pantai Baru Pandansimo
}

\author{
Reza Aditya Putra*1, Irna Tri Yuniahastuti ${ }^{2}$, Ridam Dwi Laksono ${ }^{3}$ \\ 1,2,3 Universitas PGRI Madiun, Indonesia, Fakultas Teknik, Prodi Teknik Elektro \\ e-mail: ${ }^{* 1}$ rezaaditya808@gmail.com, ${ }^{2}$ irnatri@ unipma.ac.id, ${ }^{3}$ ridam.dl@unipma.ac.id
}

\begin{abstract}
Abstrak
Indeks keandalan sistem tenaga listrik dikatakan baik atau handal yaitu ketika sistem tenaga listrik dapat menjamin ketersedian energi listrik bagi konsumen. Faktor yang menentukan tingkat keandalan sistem tenaga listrik salah satunya adalah nilai dari forced outage rate (FOR). Tingkat keandalan suatu sistem pembangkit energi listrik dapat diketahui dengan cara perhitungan LOLP (Loss of Load Probability). Pembangkit Listrik Tenaga Hibrid (PLTH) Pantai Baru Pandansimo di ketahui dengan perhitungan (Loss of Load Probability) memiliki nilai LOLP sebesar 51,3627 hari/tahun. Hal ini menunjukan sistem PLTH Pantai Baru Pandansimo tidak sesuai dengan standart PLN yaitu 1 hari/tahun. Dengan permasalahan tersebut maka dibuatlah skenario perbaikan 1 dan 2 nilai keandalan LOLP. Didalam perhitungan LOLP skenario 1 yaitu menganti grup KKP dengan unit pembangkit baru dan didapatkan lah nilai LOLP sebesar 9,6908 hari/tahun. Pada skenario 2 yaitu menambah unit pembangkit baru jadi skenario di PLTH Pantai Baru Pandansimo memiliki 4 pembangkit dan di dapatkan nilai LOLP sebesar 6,8186 hari/tahun. Pada skenario 1 dan 2 nilai nya sudah lebih baik dari pada sebelumnya tetapi belum memenuhi standart PT.PLN yaitu sebesar 1 hari/tahun
\end{abstract}

Kata kunci - FOR, Loss Of Load Probability, PLTH

\begin{abstract}
An electric power system can demonstrate the quality and capability of the electrical system in ensuring the availability of electrical energy to customer. One of the factors that determine the level of disturbance of the electric power system are the non-occurrence of disturbances or the level of forced blackouts (FOR). The level of an electrical energy generation system can be determined by calculating the LOLP (Loss of Load Probability). At the Pantai Baru Pandansimo Hybrid Power Plant (PLTH), it is known by the calculation (Loss of Load Probability) that it has a LOLP value of 51.3627 days/year. This shows that the Pantai Baru Pandansimo PLTH system is not in accordance with the PLN standard, which is 1 day/year. With these problems, scenarios for improvement of 1 and 2 values that can harm LOLP are made. In the calculation of LOLP scenario 1, namely replacing the KKP group with a new generation unit, the LOLP value is 9.6908 days/year. In scenario 2, which is adding a new generation unit, the scenario at Pantai Baru Pandansimo PLTH has 4 generators and the LOLP value is 6.8186 days/year. In scenarios 1 and 2 the value is better than before but does not meet the PT. PLN standard, which is 1 day / year
\end{abstract}

Keywords - FOR, Loss Of Load Probability, PLTH 


\section{PENDAHULUAN}

Indonesia memiliki potensi energi terbarukan yang sangat melimpah yang tersebar diseluruh daerah. Berdasarkan data dari [1], total potensi energi baru terbarukan yang ada di Indonesia mencapai 417,8 GW. Salah satu potensi EBT yang dimanfaatkan di Pantai Baru Pandansimo yaitu potensi Surya dan Bayu (angin) atau bisa disebut pembangkit listrik tenaga hibrid (PLTH). PLTH Pantai Baru Pandansimo terletak di Dusun Ngentak, Desa Poncosari, Kecamatan Srandakan, Kabupaten Bantul Yogyakarta. PLTH Pantai Baru Pandansimo memiliki 34 unit turbin angin dan 238 unit panel surya yang dapat menghasilkan daya sebesar $90 \mathrm{~kW}$ [2]. Daya yang dihasilkan dapat mencukupi kebutuhan 55 kios kuliner dan untuk digunakan di bidang pertanian. Namun, dengan berjalannya waktu unit peralatan yang berada di PLTH Pantai Baru Pandansimo banyak yang mengalami kerusakan. Hal ini disebabkan karena sejak tahun 2011 belum pernah dilakukan "Peremajan". Dampaknya yaitu kurangnya pasokan daya yang dihasilkan oleh PLTH Pantai Baru Pandansimo sehingga memberikan kerugian bagi warga setempat.

Indeks suatu keandalan sistem tenaga listrik dikatakan baik yaitu ketika sistem tenaga listrik dapat menunjukan kualitas dan kemampuan sistem kelistrikan dalam menjamin ketersedian energi listrik [3]. Tetapi pada saat unit pembangkit mengalami gangguan dalam beroperasi, maka kemungkinan daya yang dihasilkan oleh suatu pembangkit listrik berkurang dan tidak dapat melayani beban. Keadaan pembangkit listrik dalam ketersedian cadangan daya yang ada serta perubahan beban selama beroperasi akan mengakibatkan Forced outage rate (FOR). FOR adalah kegagalan unit pembangkit yang disebabkan karena adanya sesuatu hal atau gangguan yang tidak direncanakan dalam satu tahun [4]. Nilai FOR dapat diketahui dengan cara melakukan perhitungan kemungkinan terjadinya kehilangan beban atau terjadinya gangguan. Berdasarkan permasalahan diatas maka diambil judul penelitian "SKENARIO PERBAIKAN NILAI KEANDALAN LOSS OF LOAD PROBABILITY (LOLP) PADA PLTH PANTAI BARU PANDANSIMO", agar dapat mengetahui dan memperbaiki sistem tenaga listrik dengan cara membuat skenario perbaikan nilai LOLP agar sesuai dengan dengan standart yang sudah ditetapkan oleh PT. PLN pada RUPTL PLN 2015-2024 yaitu selama 1 hari/tahun [5].

\section{METODE PENELITIAN}

Pada penelitian ini, dilakukan perhitungan data menggunakan Matlab 2014a. Hasil data yang diperoleh antara lain, data beban harian selama 1 tahun, data gangguan pembangkit dan kapasitas pada tiap unit pembangkit. Selanjutnya untuk perhitungan nilai LOLP dilakukan dengan menggunakan Matlab, hasil yang diperoleh akan dianalisis kemudian akan dilakukan perbaikan dengan menggunakan skenario 1 dan skenario 2. 


\section{HASIL DAN PEMBAHASAN}

\subsection{Daya Terpasang pada PLTH Pantai Baru Pandansimo}

Data daya terpasang pada unit PLTH berdasarkan [2], ditunjukkan pada Tabel 1.

Tabel 1 Data Daya Terpasang Unit PLTH Pantai Baru Pandansimo

\begin{tabular}{cc}
\hline Grup & Daya \\
\hline Grup timur & $44 \mathrm{~kW}$ \\
Grup Barat & $36 \mathrm{~kW}$ \\
Grup KKP & $10 \mathrm{kw}$ \\
Grup KKP & $10 \mathrm{kw}$ \\
\hline
\end{tabular}

Dengan mengetahui jumlah unit pembangkit listrik di PLTH Pantai Baru Pandansimo yaitu 3 grup unit pembangkit listrik, maka diperoleh kombinasi yang dapat terjadi di sistem operasi yang ditinjau dari penyediaan daya. Dalam perhitungan kombinasi ini " $n$ " diartikan yaitu menujukan jumlah unit pembangkit sistem tenaga listrik. Berikut merupakan hasil simulasi perhitungan dengan menggunakan Matlab. Hasil perhitungan kombinasi, Pin, Pout di simulasi Matlab ditunjukkan pada Gambar 2.

$\begin{array}{ccccc}\text { I } & \text { II } & \text { III } & \text { Pin } & \text { Pout } \\ 0 & 0 & 0 & 0 & 90 \\ 0 & 0 & 1 & 10 & 80 \\ 0 & 1 & 0 & 36 & 54 \\ 0 & 1 & 1 & 44 & 46 \\ 1 & 0 & 0 & 46 & 44 \\ 1 & 0 & 1 & 54 & 36 \\ 1 & 1 & 0 & 80 & 10 \\ 1 & 1 & 1 & 90 & 0\end{array}$

Gambar 2 Hasil Perhitungan Kombinasi, Pin, Pout di Simulasi Matlab

\subsection{Menghitung Forced Outage Rate (FOR)}

Data gangguan setiap grup unit PLTH Pantai Baru Pandansimo ditunjukkan pada Tabel 2.

Tabel 2 Data Gangguan Setiap Grup Unit PLTH Pantai Baru Pandansimo

\begin{tabular}{ccc} 
Tanggal & Grup & Lama Gangguan \\
\hline 21 Januari 2014 & Grup Barat & 120 Menit \\
9 Maret 2014 & Grup Timur & 120 Menit \\
10 Maret 2014 & Grup KKP & 180 Menit \\
\hline
\end{tabular}


Mengacu pada Tabel 2, maka didapatkan nilai forced outage rate (FOR) grup timur, grup barat, grup KKP ditunjukkan pada persamaan 1 .

$$
\text { FOR }=\frac{\text { Jumlah jam gangguan unit }}{\text { Jumlah jam operasi unit }+ \text { Jumlah jam gangguan unìt }}
$$

Perhitungan Nilai FOR yaitu:

1. FOR unit grup timur

Nilai Forced Outage Rate pada unit grup timur dengan besar kapasitas $44 \mathrm{~kW}$ dan lama gangguan 120 menit.

$$
\text { FOR }=\frac{\frac{130}{60}}{24+\frac{130}{60}}=\frac{2}{24+2}=\frac{2}{26}=0,0769
$$

2. FOR unit grup barat

Nilai Forced Outage Rate pada unit grup barat dengan besar kapasitas $36 \mathrm{~kW}$ dan lama gangguan 120 menit.

$$
\text { FOR }=\frac{\frac{120}{60}}{24+\frac{1200}{60}}=\frac{2}{24+2}=\frac{2}{26}=0,0769
$$

3. FOR unit grup KKP

Nilai Forced Outage Rate pada unit grup barat dengan besar kapasitas $10 \mathrm{~kW}$ dan lama gangguan 180 menit.

$$
\text { FOR }=\frac{\frac{180}{60}}{24+\frac{180}{60}}=\frac{3}{24+3}=\frac{3}{27}=0,1111
$$

\subsection{Menghitung Kemungkinan Terjadinya atau Probabilitas Individu}

Setelah mengetahui nilai FOR di setiap unit pembangkit listrik maka langkah

\begin{tabular}{|c|c|c|c|c|}
\hline \multicolumn{4}{|l|}{ Command Window } & \multirow{2}{*}{ (1) } \\
\hline I & II & III & Probabilitas Individu & \\
\hline - & --- & - & $---x$ & \\
\hline 0.9231 & 0.9231 & 0.8889 & 0.7574 & \\
\hline 0.9231 & 0.9231 & 0.1111 & 0.0947 & \\
\hline 0.9231 & 0.0769 & 0.8889 & 0.0631 & \\
\hline 0.9231 & 0.0769 & 0.1111 & 0.0631 & \\
\hline 0.0769 & 0.9231 & 0.8889 & 0.0079 & . \\
\hline 0.0769 & 0.9231 & 0.1111 & 0.0079 & \\
\hline 0.0769 & 0.0769 & 0.8889 & 0.0053 & \\
\hline 0.0769 & 0.0769 & 0.1111 & 0.0007 & \\
\hline
\end{tabular}
selanjutnya yaitu menghitung kemungkinan terjadinya. Berikut merupakan perhitungan dan hasil simulasi Matlab untuk menghitung kemungkinan terjadinya atau probabilitas individu.

Gambar 3 Hasil Perhitungan Nilai FOR dan Probabilitas Individu di Matlab

\subsection{Perhitungan Kemungkinan Kumulatif}

Kemungkinanan kumulatif adalah kemungkinan terjadinya atau probabilitas terjadinya suatu $\mathrm{kW}$ on outage dengan nilai $\mathrm{kW}$ tertentu atau lebih. Berikut merupakan perhitungan kemungkinan kumulatif dengan matlab yang dimulai dari nilai $\mathrm{kW}$ on outage terkecil atau $0 \mathrm{~kW}$ sampai $\mathrm{kW}$ on outage terbesar atau $90 \mathrm{~kW}$. 


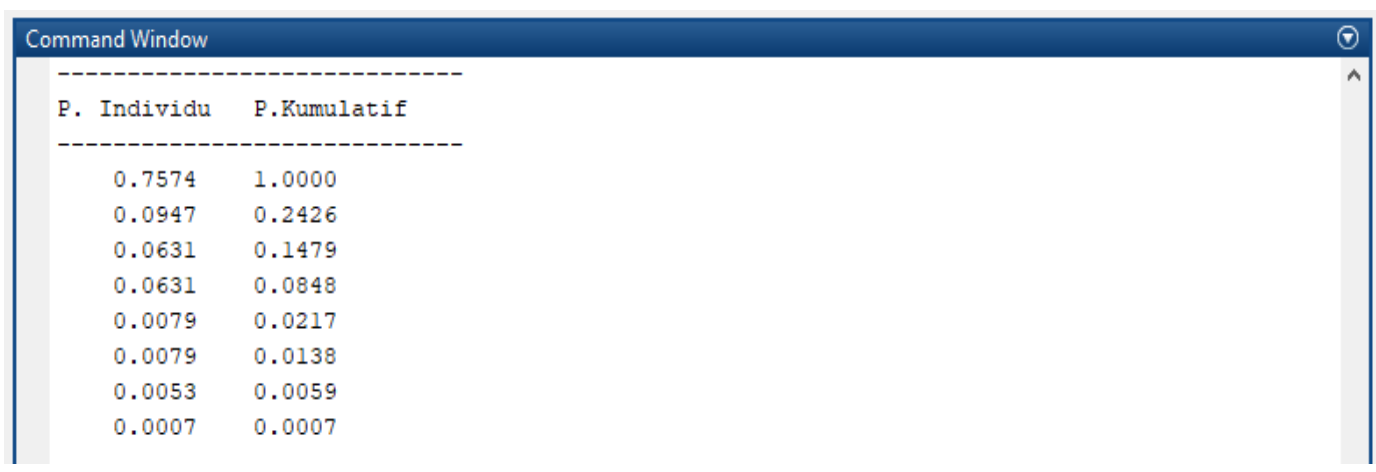

Gambar 4 Perhitungan Probabilitas Kumulatif di Simulasi Aplikasi Matlab

\subsection{Perhitungan Loss Of Load Probability (LOLP)}

1. Kurva Beban Harian

Kurva beban tahunan merupakan semua data beban selama setahun atau 364 hari. Gambar 5 merupakan kurva lama beban yang mengacu pada data beban tahun 2014.

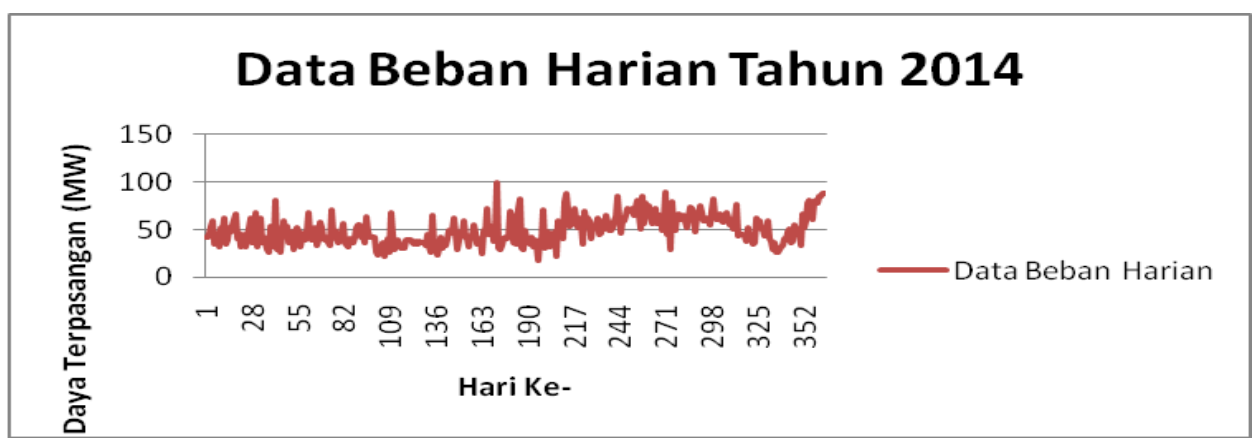

Gambar 5 Kurva Beban Harian Tahun 2014

2. Kurva Lama Beban

Setelah mengetahui kurva data beban tahunan selama 364 hari maka langkah selanjutnya mencari kurva lama beban. Kurva lama beban ditunjukkan pada Gambar 6.

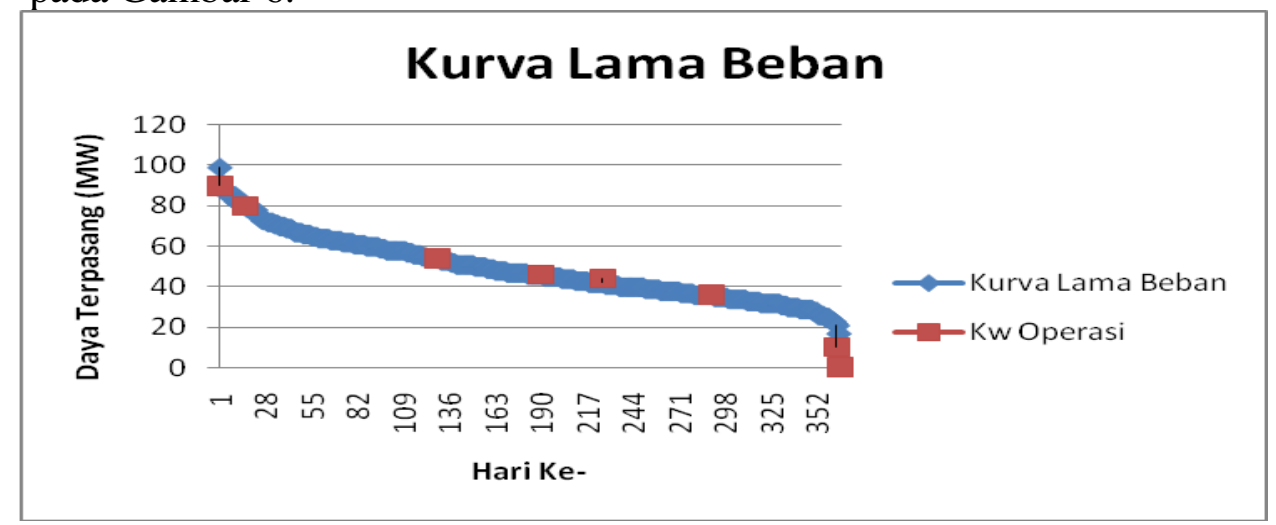

Gambar 6 Kurva Lama Beban 
Setelah menghitung dan membuat kurva lama beban maka didapatkan waktu (t) pada setiap kondisi. Langkah selanjutnya menghitung nilai loss of load probability (LOLP). Rumus LOLP ditunjukkan pada Persamaan (2).

$$
\text { LOLP = Kemungkinan Kumulatif (P) } x \text { Waktu (t) }
$$

Keterangan :

$\mathrm{P}=$ Probabilitas kumulatif atau kemungkinan kumulatif

$\mathrm{t}=$ Waktu selama 364 hari atau 1 tahun

LOLP dinyatakan dalam hari pertahun. Makin kecil nilai LOLP maka daya yang terpasang harus makin besar dan nilai forced outage rate harus semakin kecil. Dengan magsud lain perlunya investasi yang besar agar menjaga kualitas keandalan unit pembangkit [4]. Hasil simulasi perhitungan LOLP menggunakan matlab ditunjukkan pada Gambar 7.

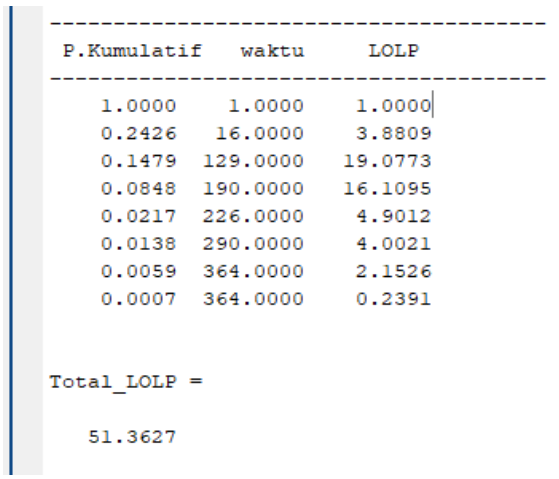

Gambar 7 Perhitungan Nilai LOLP PLTH Pantai Baru Pandansimo

Berdasarkan hasil simulasi matlab diatas didapatkan nilai LOLP sebesar 51,3627 hari/tahun yang berati sistem PLTH Pantai Baru Pandansimo tidak sesuai dengan standart PLN 1 hari/tahun. Dengan permasalahan tersebut maka dibuatlah skenario perbaikan untuk memperbaiki atau meninimalkan nilai LOLP agar PLTH Pantai Baru Pandansimo memiliki keandalan yang baik.

\subsection{Perbaikan Nilai Loss Of Load Probability (LOLP)}

1. Skenario 1 (Menganti grup KKP dengan Grup KKP baru)

Dalam perbaikan skenario 1 grup KKP kapasitas daya $10 \mathrm{~kW}$ dengan nilai FOR $=0,1111$. Dari kesemua sistem unit PLTH Pantai Baru Pandansimo ini grup KKP memiliki FOR paling besar. Oleh karena itu, grup KKP diganti grup KKP baru dengan referensi kapasitas daya dan nilai FOR sama dengan grup timur karena grup timur memiliki kapasitas daya dan nilai FOR yang baik. Grup timur memiliki kapasitas daya $44 \mathrm{~kW}$ dan nilai $\mathrm{FOR}=0,0769$. Dari skenario 1 ini didapatkan nilai LOLP sebesar 9,6908 hari/tahun. Walaupun dalam skenario perbaikan nilai keandalan LOLP di PLTH Pantai Baru Pandansimo belum memenuhi standar PT. PLN yaitu selama 1 hari/tahun.

2. Skenario 2 (Menambahkan 1 unit pembangkit baru)

Dalam perbaikan skenario 2 grup ini ditambahkan 1 unit grup pembangkit baru. Dengan referensi unit grup timur karena grup timur memiliki kapasitas daya yang besar serta memiliki nilai FOR dan daya yaitu sebesar 44 
kW dan nilai FOR sebesar 0,0769. Dari skenario 2 ini didapatkan nilai LOLP sebesar 6,8186 hari/tahun. Walaupun belum memenuhi standar PT. PLN yaitu selama 1 hari/tahun akan tetapi pada skenario ke-2 ini nilainya sudah lebih minimal dibandingkan skenario 1 yang memiliki nilai sebesar 9,6907 hari/tahun. Jadi dalam perbaikan nilai keandalan di PLTH Pantai Baru Pandansimo ini gunakanlah skenario 2 ini caranya yaitu dengan menambah 1 unit grup pembangkit baru dengan kapasitas total daya terpasang sebesar $134 \mathrm{~kW}$.

\section{KESIMPULAN}

1. Nilai LOLP pada sistem PLTH Pantai Baru Pandansimo sebesar 51,3627 hari/tahun yang berarti sistem tidak bisa melayani beban selama 51,1327 hari dalam setahun. Hal ini menunjukan sistem PLTH Pantai Baru Pandansimo tidak sesuai dengan standart PLN yaitu 1 hari/tahun

2. Dari perhitungan dan analisis skenario 1 ini didapatkan nilai LOLP sebesar 9,6908 hari/tahun. dikarenakan perbaikan skenario 1 masih tinggi maka dilakukan perbaikan skenario 2. Dari perhitungan dan analisis skenario 2 ini didapatkan nilai LOLP sebesar 6,8186 hari/tahun. Walapun belum memenuhi standart PT PLN sebesar 1 hari/tahun tetapi sudah meminimalkan nilai LOLP agar lebih mendekati standar PT. PLN.

\section{DAFTAR PUSTAKA}

[1] Direktorat Jenderal Energi Baru Terbarukan dan Konservasi Energi (Ditjen EBTKE), Buku Rencana Strategis (Renstra). Kementerian Energi dan Sumber Daya Mineral, 2020.

[2] Shindy Dewi Saras Fitri, "Analisis Indeks Keandalan Pada Pembangkit Listrik Tenaga Hibrid (PLTH) Pantai Baru Pandansimo Menggunakan Perhitungan LOLP (LOSS OF LOAD Probabil)," pp. 5-55, 2015.

[3] Muchafidhoh, "STUDI ANALISI INDEKS KEANDALAN PADA PEMBANGKIT LISTRIK TENAGA UAP (PLTU) PT. PJB UP GRESIK MENGGUNAKAN PERHITUNGAN LOLP (LOSS OF LOAD PROBABILITY)," J. Chem. Inf. Model., vol. 53, no. 9, pp. 1689-1699, 2017.

[4] R. A. Putra and I. T. Yuniahastuti, "Perhitungan Keandalan Pembangkit Loss of Load Probability ( LOLP ) untuk N unit Pembangkit," vol. 1, no. 2, pp. 13-19, 2021.

[5] Bidang Perencanaan Sistim, Rencana Usaha Penyediaan Tenaga Listrik (RUPTL) 2015-2024. PT PLN (Persero)., 2014. 